\title{
The Effect of Bay Leaf Extract (Syzygium polyanthum) on Reducing Overexpression of Matrix Metalloproteinases-13 in Acute Coronary Syndrome
}

\author{
Refli Hasan*, Gontar Alamsyah Siregar, Dharma Lindarto \\ Department of Internal Medicine, Faculty of Medicine, Universitas Sumatera Utara, Haji Adam Malik General Hospital, Medan, \\ North Sumatera, Indonesia
}

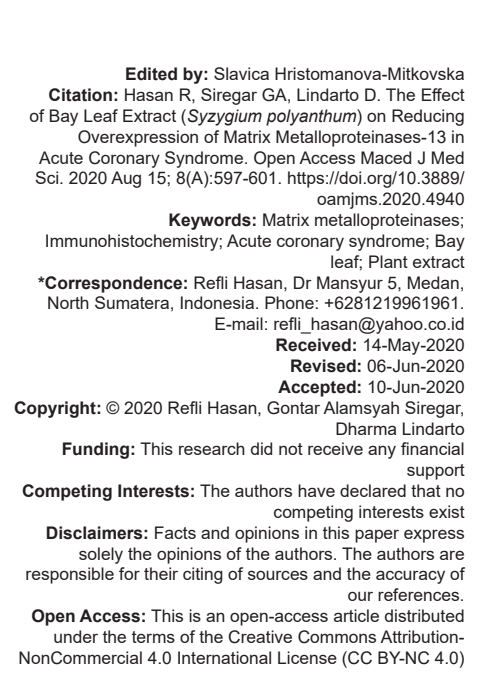

\begin{abstract}
AIM: The objective of the study was to determine the inhibitory effect of bay leaf (Syzygium polyanthum) on matrix metalloproteinases (MMPs) (MMP-9 and MMP-13) inhibitory effect in surgery-induced acute coronary syndrome (ACS) rat model.

METHODS: This study was experimental animal study. Thirty-two surgery-induced ACS Wistar rats (Rattus norvegicus) divided into 16 bay leaf extract (treatment) group and 16 control groups were sacrificed on days 1,3 7, and 14 after induction. Expressions of MMP-9 and MMP-13 were determined by immunohistochemistry and its scoring was assessed by two-blinded experienced pathologists. The immunohistochemical scoring of MMP-9 and MMP-13 between groups was analyzed using independent sample t-test and within groups by using one-way ANOVA test.

RESULTS: The expression of MMP-13 in treatment group was decreased compared to control group on days 7 and 14 ( $p=0.001$ and $p=0.015$, respectively). Compared to day 1 , the reduction expression of MMP-13 was significant in both control group and treatment group $(p=0.009$ and $p=0.003$, respectively). There were no significant changes in expression of MMP-9 between groups, and within control group and treatment group.
\end{abstract}

CONCLUSION: Bay leaf can reduce the overexpression of MMP-13 in surgery-induced ACS rat model. Bay leaf extract can be considered to be given as an adjuvant to prevent cardiovascular adverse event and adverse cardiac remodeling post-ACS.

\section{Introduction}

Coronary heart disease is one of the major causes of mortality in people older than 35 years that were usually caused by atherosclerotic process in coronary arteries, better known as coronary artery disease (CAD) [1]. Acute coronary syndrome (ACS) is symptomatic CAD and further classified into ST-elevation acute myocardial infarction and non-ST-elevation ACSs [2]. Progression of ACS is thought as a result from sudden luminal narrowing by thrombosis, mostly by plaque rupture [3]. Plaque rupture is caused by destruction of extracellular matrix due to increased production of matrix metalloproteinases (MMPs) by macrophages during atherosclerosis process in response to inflammatory stimuli and oxidative stress [4], [5].

Some MMPs (such as MMP-9 and MMP-13) have important role in cardiovascular diseases and myocardial remodeling, especially in ACS [6], [7]. Gelatinase B, widely known for MMP-9, degrades Type IV collagen and elastin [8] and increased concentration was associated with plaque rupture during acute phase of ACS [9]. As MMP-9 can differentiate ACS with ruptured plaques from non-ruptured plaques, it might have a predictive value of mortality [10] and correlate to acute heart failure event [11]. Whereas, MMP-13 has role in platelet aggregation and thrombus formation and correlates positively with enhanced plaque vulnerability and rupture [7].

Bay leaf (Syzygium polyanthum), better known as salam leaf in Indonesia, is an easily accessible traditional Indonesian herbal medicine with many pharmacological activities, such as anti-inflammatory, antioxidant, anticholesterol, and antiplatelet [12], [13]. Flavonoid, tannin, and saponin compounds were suspected to be the active compound in bay leaf to reduce cholesterol level, arterial damage protection, and deposition of cholesterol on arterial endothelium [12], [14] by modulating MMPs [15], [16]. Flavonoid has inhibitory effect on overexpressed MMPs in cardiovascular disease [17]. This study aims to demonstrate the 
MMPs (MMP-9 and MMP-13) inhibitory effect of bay leaf on rat model with ACS

\section{Methods}

\section{Animals and study design}

This study was experimental animal study. Animal handling was conducted in Animal House, Research Laboratory, School of Medicine, Universitas Brawijaya, Malang, Indonesia. Histopathological analysis was conducted in Biochemical and Molecular Biology Laboratory of the Medical Faculty of Universitas Brawijaya Malang, Indonesia. All procedures were conducted in December 2019. The experiment was approved by The Institutional Ethics Committee of Universitas Sumatera Utara, Medan, Indonesia.

Thirty-two male healthy Wistar rats (Rattus norvegicus), 10-12 weeks old and weighing $200 \mathrm{~g}$, were housed at $20-25^{\circ} \mathrm{C}$ with controlled $12 \mathrm{~h}$ light/dark cycle. Laboratory-standardized cages were used to keep the animals with free access to food and water. Thirty-two surgical-induced myocardial infarction rats were divided into two groups: Control group (16 rats) and treatment group (16 rats). Treatment group was given ethanol extract of bay leaf in sodium carboxymethyl cellulose (3.6 mg/rats) [18] through orogastric tube. Bay leaf (S. polyanthum) extract was prepared by maceration [19] in the research unit laboratory, School of Medicine, Universitas Brawijaya, Malang, Indonesia. Four rats each from both groups were sacrificed on days 1, 3, 7, and 14 . Immunohistochemical analysis of MMP9 and MMP13 was conducted to these rats.

\section{Surgical induction of myocardial infarction}

The experimental myocardial induction was done by ligation of coronary artery [13]. Rat was anesthetized by ketamine before the surgery. Thoracotomy followed by permanent ligation of left anterior descending artery was conducted until sign of myocardial induction was seen (blanching area distal to the ligation) [20]. Thorax and skin were sutured and rat was left to recover.

\section{Immunohistochemical analysis of MMP9 and MMP13}

The heart specimens were paraffin-embedded and subsequently cut into 4 to 6 micron thick using microtome. The chosen paraffin-embedded slides were deparaffinized, rehydrated, and heated on microwave with $10 \mathrm{mM}$ sodium citrate buffer $(\mathrm{pH} \mathrm{6.0)}$ for $10 \mathrm{~min}$ at $95^{\circ} \mathrm{C}$, then allow the slides to cool in the buffer for
20 min. Endogen peroxidase activity was blocked with $1 \%$ hydrogen peroxide for $5 \mathrm{~min}$, and then washed with PBS twice for 5 min each. The specimens were incubated overnight in $4{ }^{\circ} \mathrm{C}$, and then immune stained with MMP-9 antibody (E-11; sc-393859) and MMP-13 antibody (H-230; sc-30073) primary antibodies from Santa Cruz Biotechnology, Inc. (Dallas, TX, USA) in concentration of $200 \mu \mathrm{g} / \mathrm{mL}$ diluted by $1: 1000$. Primary antibody was detected by avidin-biotin peroxidase solution (VECTASTAIN Elite ABC kit) from Vector Laboratories (Burlingame, CA, USA) and signal was visualized by using 3,3'-diaminobenzidine from Sigma-Aldrich (Missouri, USA). The slides then counterstained with hematoxylin and assessed by two-blinded experienced pathologists. Slides were scored for positive cells and intensity of staining. Positive cells were scored as (0) for $<10 \%$ stained, (1) for $10-25 \%$ stained, (2) for $25-50 \%$ stained, (3) for $50-75 \%$ stained, and (4) for $75-100 \%$ stained. Intensity of staining was scored as (1) for weak intensity, (2) for moderate, and (3) for strong intensity. Slides scoring of immunohistochemical staining was positive cells multiplied by intensity of staining.

\section{Statistical analysis}

The immunohistochemical scoring of MMP-9 and MMP-13 between groups was analyzed using independent sample t-test (normal data distribution) or Mann-Whitney U-test (data distribution not normal). The results were also analyzed using one-way ANOVA test (normal data distribution) or Kruskal-Wallis test (data distribution not normal) to compare between days within treatment group and also control group. Bonferroni post hoc test were conducted if there was significant differences using one-way ANOVA test. Mann-Whitney U-test comparing day 1 with each day 3,7 , and 14 was conducted if there were significant differences using Kruskal-Wallis test. The differences were considered statistically significant when $p<0.05$.

\section{Results}

Slides were examined for the expression of MMP-9 (Figure 1) and MMP-13 (Figure 2), then were compared between groups by immunohistochemistry scoring on days $1,3,7$, and 14 (Table 1). The immunohistochemistry score of MMP-13 was significantly lower in treatment group compared to control group on days 7 and 14 ( $p=0.001$ and $p=0.015$, respectively). Compared to day 1 , there was significant decrease in immunohistochemistry score of MMP-13 on either control group $(F(3,12)=$ $6.044, p=0.009)$ and treatment group $(F(3,12)=7.952$, $p=0.003$ ). From post hoc analysis, immunohistochemistry score of MMP-13 from control group was significantly decreased on days 3,7 , and $14(p=0.044, p=0.028$, and $p=0.019$, respectively) compared to day 1 , and from 


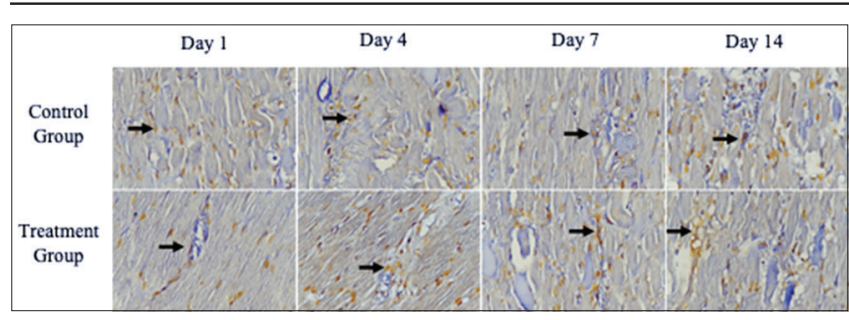

Figure 1: Immunohistological slides of matrix metalloproteinases (MMP)-9 expression on myocardial of surgical-induced acute coronary syndrome (ACS) rats. Row 1 shows myocardial MMP-9 expression of surgically-induced ACS rats without treatment, whereas Row 2 shows myocardial MMP-9 expression of surgically-induced ACS rats with bay leaf extract as treatment. Black arrow indicates the expression of MMP-9

treatment group was significantly decreased only on days 7 and 14 ( $p=0.024$ and $p=0.004$ ) (Figure 3). There were no significant changes in expression of MMP-9 on treatment group compared to control group, and when compared to day 1 , there were no significant changes in immunohistochemistry score of MMP-9 on either control or treatment groups (Figure 4).

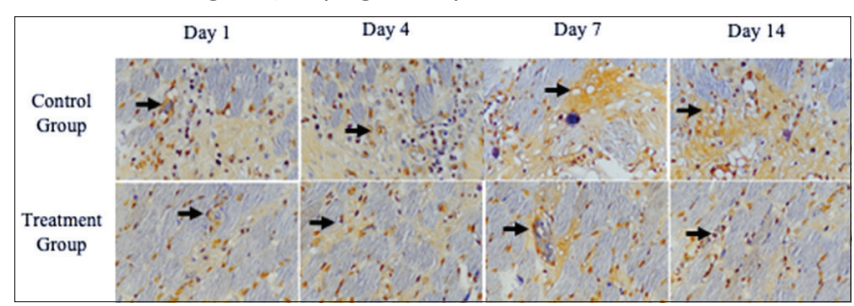

Figure 2: Immunohistological slides of matrix metalloproteinases (MMP)-13 expression on myocardial of surgical-induced acute coronary syndrome (ACS) rats. Row 1 shows myocardial MMP-13 expression of surgically-induced ACS rats without treatment, whereas Row 2 shows myocardial MMP-13 expression of surgically-induced ACS rats with bay leaf extract as treatment. Black arrow indicates the expression of MMP-13

\section{Discussion}

Atherosclerotic plaque rupture can be caused by overexpression of MMPs, especially MMP-9 and MMP-13 [4], [7], [10]. Higher serum MMP-9 was found in acute phase of ACS and gradually resolves during recovery [9]. Bay leaf extract has flavonoid compound that reduces cholesterol level, protecting arteries from damage, and reducing deposition of cholesterol on arterial endothelium [12], [14] by inhibiting overexpressed MMPs in cardiovascular disease [15], [16], [17]. This finding, however, is

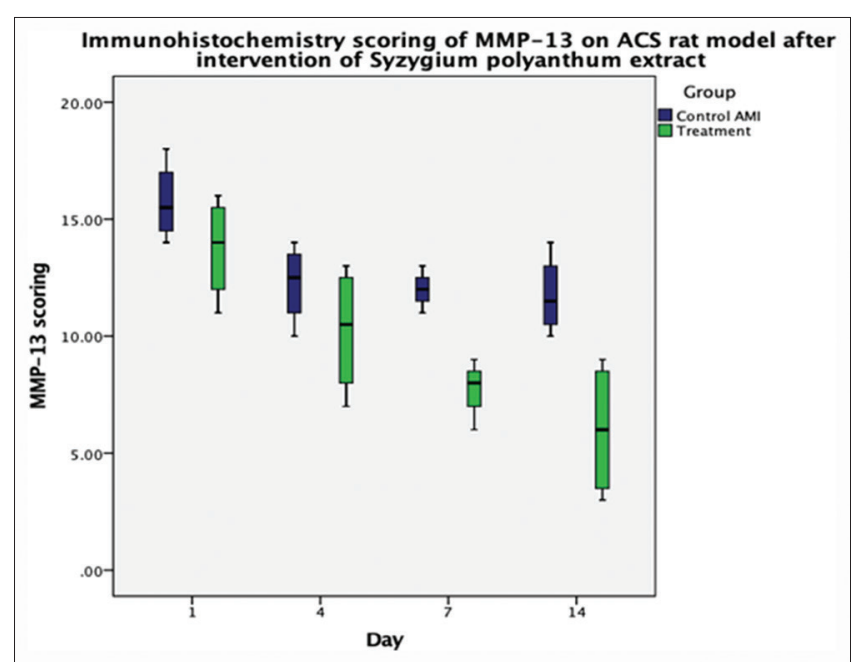

Figure 3: Expression of matrix metalloproteinases-13 on acute coronary syndrome rat model compared between treatment and control groups

discordant to our study which shows there were no significant differences of MMP-9 expression between control and group treatment, within control group, and within treatment group. This discordant result might be due to MMP-9 was undetectable in the infarcted region, but higher in remote region [21] and due to differences between expression of MMP-9 in rats and humans [4]. Study by Huang et al., shows higher expression of MMP-9 in human compared to rats [22].

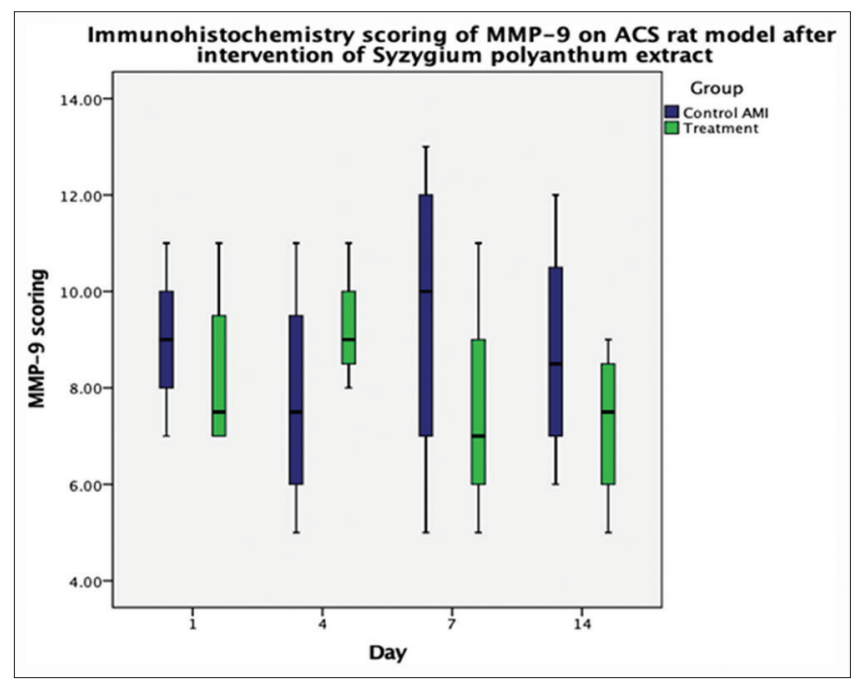

Figure 4: Expression of matrix metalloproteinases-9 on acute coronary syndrome rat model compared between treatment and control groups

Table 1: Comparison of MMP-9 and MMP-13 on immunohistochemistry score between control group and treatment group*

\begin{tabular}{|c|c|c|c|c|c|c|c|c|c|c|}
\hline \multirow[t]{3}{*}{ Day } & \multicolumn{10}{|c|}{ Immunohistochemistry score (mean [SD]) } \\
\hline & \multicolumn{5}{|l|}{ MMP-9 } & \multicolumn{5}{|l|}{ MMP-13 } \\
\hline & $\begin{array}{l}\text { Control } \\
\text { group }\end{array}$ & $\begin{array}{l}\text { Treatment } \\
\text { group }\end{array}$ & $\begin{array}{l}\text { Mean difference } \\
(95 \% \mathrm{Cl})\end{array}$ & $\begin{array}{l}\text { t-statistic } \\
\text { (df) }\end{array}$ & $\mathrm{p}$ & $\begin{array}{l}\text { Control } \\
\text { group }\end{array}$ & $\begin{array}{l}\text { Treatment } \\
\text { group }\end{array}$ & $\begin{array}{l}\text { Mean difference } \\
(95 \% \mathrm{Cl})\end{array}$ & $\begin{array}{l}\text { t-statistic } \\
\text { (df) }\end{array}$ & $p$ \\
\hline 1 & $9.00(1.63)$ & $8.25(1.89)$ & $0.75(-2.3,3.8)$ & $0.60(6)$ & 0.570 & $15.75(1.71)$ & $13.75(2.22)$ & $2.00(-1.42,5.42)$ & $1.43(6)$ & 0.203 \\
\hline 3 & $7.75(2.50)$ & $9.25(1.26)$ & $-1.50(-4.92,1.92)$ & $-1.07(6)$ & 0.325 & $12.25(1.71)$ & $10.25(2.75)$ & $2.00(-1.96,5.96)$ & $1.23(6)$ & 0.263 \\
\hline 7 & $9.50(3.42)$ & $7.50(2.52)$ & $2.00(-3.20,7.20)$ & $0.94(6)$ & 0.382 & $12.00(0.82)$ & $7.75(1.26)$ & $4.25(2.41,6.09)$ & $5.67(6)$ & 0.001 \\
\hline 14 & $8.75(2.50)$ & $7.25(1.71)$ & $1.50(-2.20,5.20)$ & $0.99(6)$ & 0.360 & $11.75(1.71)$ & $6.00(2.94)$ & $5.75(1.59,9.91)$ & $3.38(6)$ & 0.015 \\
\hline
\end{tabular}


In vitro study by Howes et al. shows MMP. 13 role in platelet aggregation inhibition and thrombus formation [23]. This protease is upregulated in atherothrombotic and inflammatory conditions [24]. Higher level of MMP-13 enhanced plaque vulnerability and rupture of plaques [25]. Study by Wilson et al., shows there is increased MMP-13 expression in infarcted region [21]. Our study shows there are significant reduction in MMP-13 expression in bay leaf extract ACS-induced rat compared to control. This finding might be resulted from flavonoid compound of bay leaf extract which inhibits expression of MMPs [15], [16], [17]. Although there were significant decrease in MMP-13 expression in both control and treatment compared to day 1, there was always lower MMP-13 expression on treatment group compared to control. Inhibition of MMP-13 overexpression yields to collagen accumulation in plaques therefore increases the rupture resistance of plaques [26].

Reducing the overexpression of MMPs in heart disease may modify adverse the development of cardiac remodeling [6]. Although there were differences between human and rat expression of MMPs [4] which are within our limitation of study, this study shows the promising bay leaf pharmacological potential inhibition of MMP-13 in reducing cardiovascular adverse event and development of better cardiac remodeling postACS. Flavonoid active compound of bay leaf extract which might be responsible in modification of MMPs expression should be identified further for the potential in myocardial infarction.

\section{Conclusion}

Bay leaf can reduce the overexpression of MMP-13 in surgery-induced ACS rat model. Bay leaf extract can be considered to be given as an adjuvant to prevent cardiovascular adverse event and adverse cardiac remodeling post-ACS.

\section{References}

1. Sanchis-Gomar F, Perez-Quilis C, Leischik R, Lucia A Epidemiology of coronary heart disease and acute coronary syndrome. Ann Transl Med. 2016;4(13):256. https://doi. org/10.21037/atm.2016.06.33

PMid:27500157

2. Setianto BY, Mubarika S, Irawan B, Astuti I. Association between high serum matrix metalloproteinase-9 and MMP-9 $(-1562 \mathrm{C}>\mathrm{T})$ polymorphism in patients with ST-elevation acute myocardial infarction. Cardiol Res. 2012;3(5):222-9. https://doi. org/10.4021/cr210w

PMid:28348691
3. Akasaka T, Kubo T, Mizukoshi M, Tanaka A, Kitabata $H$, Tanimoto T, et al. Pathophysiology of acute coronary syndrome assessed by optical coherence tomography. J Cardiol. 2010;56(1):8-14. https://doi.org/10.1016/j.jjcc.2010.05.005 PMid:20554431

4. Newby AC. Metalloproteinase production from macrophages-a perfect storm leading to atherosclerotic plaque rupture and myocardial infarction. Exp Physiol. 2016;101(11):1327-37. https://doi.org/10.1113/ep085567

PMid:26969796

5. Hamed GM, Fattah MF. Clinical relevance of matrix metalloproteinase 9 in patients with acute coronary syndrome. Clin Appl Thromb Hemost. 2015;21(8):705-11. https://doi. org/10.1177/1076029614567309

PMid:25616488

6. Spinale FG, Villarreal F. Targeting matrix metalloproteinases in heart disease: Lessons from endogenous inhibitors. Biochem Pharmacol. 2014;90(1):7-15. https://doi.org/10.1016/j. bcp.2014.04.011

PMid:24780447

7. Montague SJ, Gardiner EE. Matrix metalloproteinase-13 unlucky for the forming thrombus. Res Pract Thromb Haemost. 2018;2(3):525-8. https://doi.org/10.1002/rth2.12105 PMid:30046757

8. Van Doren SR. Matrix metalloproteinase interactions with collagen and elastin. Matrix Biol. 2015;44-46:224-31. https://doi. org/10.1016/j.matbio.2015.01.005 PMid:25599938

9. Lahdentausta L, Leskelä J, Winkelmann A, Tervahartiala T, Sorsa T, Pesonen E, et al. Serum MMP-9 diagnostics, prognostics, and activation in acute coronary syndrome and its recurrence. J Cardiovasc Transl Res. 2018;11(3):210-20. https://doi.org/10.1007/s12265-018-9789-x PMid:29349668

10. Kobayashi N, Takano M, Hata N, Kume N, Tsurumi M, Shirakabe A, et al. Matrix metalloproteinase- 9 as a marker for plaque rupture and a predictor of adverse clinical outcome in patients with acute coronary syndrome: An optical coherence tomography study. Cardiology. 2016;135(1):56-65. https://doi. org/10.1159/000445994

PMid:27271099

11. Hadipurnomo S, Setianto BY, Dinarti LK. Correlation of serum levels of matrix metalloproteinase-9 to acute heart failure event as a complication af acute coronary syndrome. Acta Cardiol Indones. 2015;1(1):8-12

12. Novira PP, Febrina E. Review of pharmacological activity of bay leaf extract (Syzygium polyanthum (Wight.) Walp). Farmaka. 2018;16:288-97.

13. Hasan R, Lindarto D, Siregar GA, Mukhtar Z. The effect of bay leaf extract Syzygium polyanthum (Wight) Walp. On C-reactive protein (CRP) and myeloperoxidase (MPO) level in the heart of rat model of myocardial infarction. Med Glas (Zenica). 2020;17(1):1-5

PMid:31601063

14. A'Yun NQ, Sari NP, Putra RS. The effect of Salam leaf (Syzygium polyanthum Wight) decoction to reduce uric acid levels in humans' blood: An attempt to globalize traditional medicine. In: Proceeding Book $7^{\text {th }}$ Asian Academic Society International Conference; 2019. p. 253-6.

15. Raychaudhuri S, Ghosh S, Roy A, Swarnakar S. Protective role of black tea flavonoids against ethanol-induced gastropathy via matrix metalloproteinase pathway. Indian J Clin Biochem. 2019;34(4):379-94. https://doi.org/10.1007/s12291-018-0762-x PMid:31686725

16. Haleagrahara N, Hodgson K, Miranda-Hernandez $\mathrm{S}$, 
Hughes S, Kulur AB, Ketheesan N. Flavonoid quercetinmethotrexate combination inhibits inflammatory mediators and matrix metalloproteinase expression, providing protection to joints in collagen-induced arthritis. Inflammopharmacology. 2018;26(5):1219-32. https://doi.org/10.1007/s10787-018-0464-2 PMid:29616452

17. Anajafi T, Sedigh A, Mallik S. Naturally occurring matrix metalloproteinase inhibitors:Agroup of promising cardioprotective agents: Promises and hopes. In: Cardioprotective Natural Products: Promises and Hopes. Singapore: World Scientific; 2017. p. 9-46. https://doi.org/10.1142/9789813231160_0002

18. Syahreza A, Syafril S, Lindarto D. Comparison of sambiloto (Andrographis paniculata (Burm. f.) Nees) and Salam (Syzygium polyanthum (wight) walp) extract mixture with simvastatin on ferritin concentration in dyslipidemic patients. J Med Plants Stud. 2018;6(6):4-7.

19. Hartanti L, Yonas SM, Mustamu JJ, Wijaya S, Setiawan HK, Soegianto L. Influence of extraction methods of bay leaves (Syzygium polyanthum) on antioxidant and HMG-CoA reductase inhibitory activity. Heliyon. 2019;5(4):e01485. https:// doi.org/10.1016/j.heliyon.2019.e01485 PMid:31008409

20. Wu Y, Yin X, Wijaya C, Huang MH, McConnell BK. Acute myocardial infarction in rats. J Vis Exp. 2011;48:2464. PMid:21372786

21. Wilson EM, Moainie SL, Baskin JM, Lowry AS, Deschamps AM, Mukherjee R, et al. Region-and type-specific induction of matrix metalloproteinases in post-myocardial infarction remodeling. Circulation. 2003;107(22):2857-63. https://doi.org/10.1161/01. cir.0000068375.40887.fa
PMid: 12771000

22. Huang W, Sala-Newby GB, Susana A, Johnson JL, Newby AC. Classical macrophage activation up-regulates several matrix metalloproteinases through mitogen activated protein kinases and nuclear factor-кB. PLoS One. 2012;7(8):e42507. https:// doi.org/10.1371/journal.pone.0042507

PMid:22880008

23. Howes J, Pugh N, Hamaia SW, Jung SM, Knauper V, Malcor J, et al. MMP-13 binds to platelet receptors $\alpha \mathrm{llb} \beta 3$ and GPVI and impairs aggregation and thrombus formation. Res Pract Thromb Haemost. 2018;2(2):370-9. https://doi.org/10.1002/rth2.12088 PMid:30046741

24. Amar S, Smith L, Fields GB. Matrix metalloproteinase collagenolysis in health and disease. Biochim Biophys Acta Mol Cell Res. 2017;1864(11):1940-51. https://doi.org/10.1016/j. bbamcr.2017.04.015

PMid:28456643

25. Sukhova GK, Schönbeck U, Rabkin E, Schoen FJ, Poole AR, Billinghurst RC, et al. Evidence for increased collagenolysis by interstitial collagenases- 1 and -3 in vulnerable human atheromatous plaques. Circulation. 1999;99(19):2503-9. https:// doi.org/10.1161/01.cir.99.19.2503

PMid: 10330380

26. Quillard T, Tesmenitsky Y, Croce K, Travers R, Shvartz E, Koskinas KC, etal. Selective inhibition of matrix metalloproteinase 13 (MMP-13) increases collagen content of established mouse atheromata. Arterioscler Thromb Vasc Biol. 2011;31(11):246472. https://doi.org/10.1161/atvbaha.111.231563

PMid:21903941 